"co-adapted meme complexes" that include a stimulus for imitation ("good girls don't have sex before marriage"), and into even larger "memeplexes", such as religion, with many copy-able elements. Like Sherlock Holmes, Blackmore sees our brain as a room of limited size that can store only so many memes. A meme's success depends not on its benefits to the carrier, but on its ability to be replicated, retained and imitated. As she declares persistently: "If a meme can get itself successfully copied it will." According to Blackmore, this shibboleth explains major aspects of our biology and culture, including oversized brains, language, technology, writing, contraception, adoption, altruism, vegetarianism, New Age ideas such as alien abduction, and consciousness.

Such an ambitious theory demands close scrutiny, but space restricts me to exploring only a few of Blackmore's views. She suggests, for example, that enlargement of the human brain began when natural selection improved the ability to imitate, followed by selection for ever more neurons to store successful memes. Blackmore contends that such selection has occurred only in hominids and birds that learn songs. Subsequently, memes further expanded our brain through sexual selection: as better imitators, bigger-brained individuals are more attractive mates and leave more offspring.

One immediately smells trouble. First, there is no evidence that brain-size increase had anything to do with memes - there are as many explanations (including language, social grouping, hunting) as there are evolutionists, and no way to judge which theory is best. Indeed, the meme hypothesis seems among the least likely. As others have noted, the serious proliferation of memes began roughly 30,000 years ago when humans commenced their march to larger social groups, writing and complex culture. The human brain, however, stopped enlarging after reaching its present volume nearly 500,000 years ago. Why did brain-size evolution stop so long before the heaviest rain of memes?

Although Blackmore deems memetics a scientific idea, nearly all of her suggested tests are either impossible to perform or unable to rule out competing theories. For example, she claims support for the sexual selection of memes, declaring that "... being highly articulate makes you sexually attractive. The history of love poems and love songs suggests as much, as does the sexual behaviour of politicians, writers, and television stars." This may be true, but Blackmore has forgotten sports heroes, rock stars and supermodels, also highly attractive but hardly known for eloquence. The combined data better

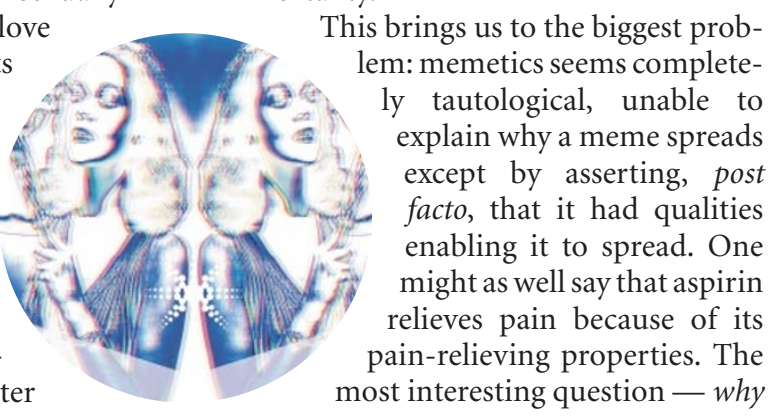
m: memetics seems completetautological, unable to explain why a meme spreads except by asserting, post facto, that it had qualities enabling it to spread. One might as well say that aspirin relieves pain because of its most interesting question - why support the sociobiological theory that humans (especially females) are attracted by power and its attendant resources.

Narrower hypotheses have additional difficulties. A frequent problem is that the supposed meme seems to discourage its own propagation. Such a case is Blackmore's view that celibacy in Catholic priests is a meme that spreads by forcing clergy to divert their sexual energy into serving their religion. But what memes spring from this suppressed sperm? If priests beseech their flocks to forever refrain from reproduction, it is news to me. Other religions with non-celibate clerics, such as Islam, seem to have no trouble attracting believers.

Finally, Blackmore sees consciousness as a "selfplex", an insidious band of memes that conspire to give their carrier a false sense of self. Consciousness permits personal conviction, said to be especially good for encouraging imitation (for example, "I love beer"). However, consciousness cannot be illusory: as the American philospher John Searle has argued, thinking one is conscious is identical to being conscious. Moreover, Blackmore's scenario denies the possibility of consciousness to meme-less animals, and fails to explain the hardest problem of human consciousness: subjective sensation. How can memes account for the pain I feel when I pinch myself?

But this is mere quibbling, for Blackmore's enterprise has two fatal flaws. First, she has got the chain of causation backwards. The claim that memes created major features of humanity is equivalent to the claim that the main force driving the development of better computers has been the self-propagation of software. In reality, computers are usually designed for speed and capacity, which then permits the development of new software. Similarly, the selfreplication of memes does not mould our biology and culture; rather, our biology and culture determine which memes are created and spread. What a world of human psychology is obscured by Blackmore's mantra, "If a meme can get itself successfully copied it will"! To me, memetics boils down to the following obvious theory: ideas tend to spread if they cater to our desires to have love, comfort, pleasure, power, sex, the attention and admiration of others, a meaningful life and a way to evade the awful fact of mortality.

This brings us to the biggest prob- some memes spread and not others - is completely neglected. Why did Christianity take hold during the waning days of the Roman Empire? You won't find the answer, or any way to attain it, in memetics. (This, by the way, makes memetics utterly unlike biological evolution. The spread of genes through natural selection is not tautological because one can predict their fate through their known effects on replication and the reproduction of their carriers.)

In a final effort to propagate her ideas, Blackmore constructs an extremely clever coadapted meme complex: "Evolutionary theory faced enormous opposition because it provided a view of humans that many humans do not like. The same will probably be true of memetics." Well, call me Bishop Wilberforce, but in my view memetics is but a flashy new wrapping around a parcel of old and conventional ideas.

Jerry A. Coyne is in the Department of Ecology and Evolution, The University of Chicago, 1101 East 57 Street, Chicago, Illinois 60637, USA.

\section{Shady secrets of the Enlightenment}

\section{Sex and the Gender Revolution, Volume 1: Heterosexuality and the Third Gender in Enlightenment London}

by Randolph Trumbach

University of Chicago Press: 1998. 484 pp. $\$ 35, £ 27.95$

\section{W.F.Bynum}

Sex and bodies have become fashionable historical topics. Indeed, there are those who believe that historians are a prurient lot, preferring the bedroom to the laboratory, hospital, battlefield, palace and other sites where activities traditionally deemed more worthy of historical analysis take place.

Prurient or not, historians and social scientists quite correctly insist that bedroom behaviour can be exceptionally difficult to analyse. One of Randolph Trumbach's adulterers stuffed a handkerchief in the keyhole of her bedroom door, so that her servants could not spy on her. Even his randy men, who went with prostitutes in parks, alehouses or dark alleyways, were unlikely to leave detailed accounts of their escapades. This, of course, makes eighteenth-century diarists such as James Boswell and William Byrd so attractive to historians, even if their class and status make them unsuitable for generalization about male behaviour down the ranks.

For the most part, then, Trumbach's account of heterosexuality in eighteenthcentury London relies on other kinds of evidence, including newspapers, diaries, correspondence and imaginative literature. 


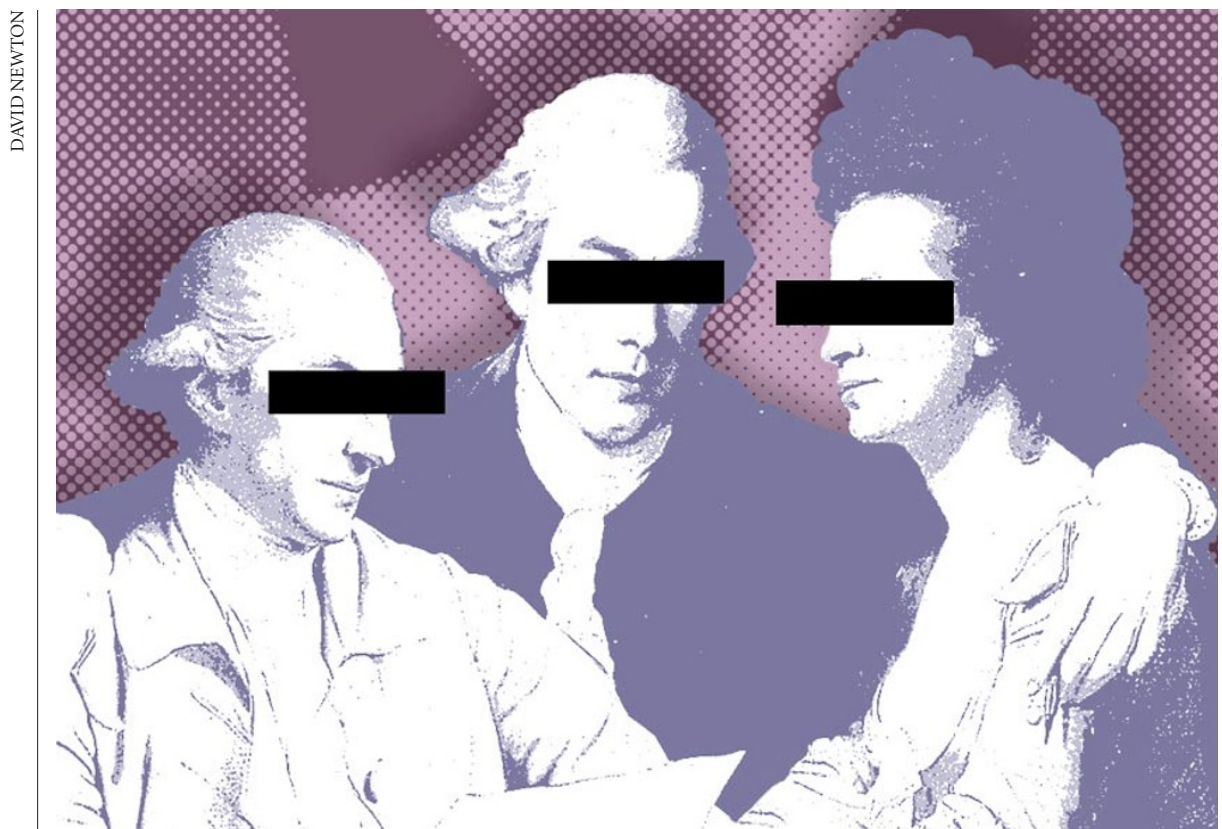

The Bishop of London's consistory court heard suits for divorce and defamation. Magistrates' courts, Old Bailey papers and quarter-session rolls contain information on prostitutes and sexual crimes of violence as well as divorce. The archives of the Lock and Foundling hospitals reveal the fruits of illicit sexual activity among the poor, and Poor Law records are concerned especially with illegitimacy.

This diverse range of sources allows Trumbach to cut across class (since the poor did not leave diaries) and gender (both sexes sued for divorce and were treated for venereal disease). It also permits him to follow over time a range of parameters relating to the sexual lives of Londoners. These include prostitution, rape, bastardy, masturbation, courtship, domestic violence and adultery.

Whenever possible, Trumbach has quantified his data. Thus, we can learn things we never knew before about the occupations of men arrested for whoring or seducing women who subsequently offered their babies to the Foundling Hospital; the ages of spinsters making bastardy declarations in Chelsea or St Martin-in-the-Fields; and the gender and marital status of keepers of bawdy houses. The statistics are leavened by his reconstructions of the sexual histories of dozens of ordinary women and men whose passions and lusts, joys and sorrows, adventures and miscalculations brought them into the jurisdiction of the institutions of authority.

Through the subtlety of his analyses and the elegance of his prose, Trumbach has reached new heights in the study of historical sexuality. He has an impressive mastery of his material, on which he has been working for more than two decades, and an intimate knowledge of the geography and social history of eighteenth-century London. He has intriguing things to say about the changing role of romanticism and sentimentality in both marriage and extramarital sex, and about the harsh realities of being an unmarried woman two centuries ago, when a proposal of marriage was sometimes an outcome of rape.

The nature of the available records of necessity leads Trumbach to a fairly bleak picture of human sexual conduct. Tolstoy reminded us long ago that "All happy families resemble one another, but each unhappy family is unhappy in its own way". Trumbach might have reflected on the fact that happy families, and happy relationships, rarely leave traces in the kinds of legal and institutional records he has mined. This is important, because Trumbach's picture of brutal and often violent sexual encounters between men and women is fundamental to the book's central thesis, one of breathtaking originality and, maybe, audacity.

That thesis is this: until about 1700, in London but probably also throughout Europe, neither effeminate, exclusive homosexuality, nor obligate heterosexuality, existed. Rather, the dominant sexual pattern was the one that we know existed in ancient Greece, and which Michael Rocke has recently argued also obtained in Renaissance Florence - about half the male population had same-sex experience during adolescence. Within this framework, sexual behaviour was regulated by age, and middle-aged men would routinely have slept with adolescent boys. Christian teaching castigated homosexuality, of course, but until 1700 or so, Trumbach suggests, these two morality systems existed side by side, with the official one dictating public and legal utterances even while the other one governed private behaviour. The consequences were the relative unimportance of prostitution, as men found other outlets for their sexuality, and a much more tolerant, if rarely articulated, attitude towards sexual expression of all kinds.

Trumbach is silent about what ushered in the new regime of obligate heterosexuality. But after 1700, under this new regime, he insists, males felt compelled to exercise exclusive heterosexuality. Sodomy, even with women, was criminalized, and masturbation was medicalized into the dangerous practice of onanism, against which sermons and medical tracts were produced in profusion. Any underground homosexual activity that still existed was continued by a minority of exclusively homosexual males - the "third gender" of Trumbach's subtitle. Exclusive female homosexuality did not emerge, he believes, until about 1770; until then, females were denied any but heterosexual experience. This regime, which emerged within a single generation, lasted until about 1960, when gay consciousness and activism made homosexuality more visible, and bisexuality became possible once more.

Trumbach's bold scheme must be largely speculative, of course, given the large historical silences surrounding most aspects of human sexuality. The present volume is the first of a promised brace and focuses almost exclusively on the male-female consequences of what he frequently calls the "new male heterosexuality". Implicit in his scheme is the assumption that the old regime was somehow gentler, that males with homosexual outlets are less likely to need prostitutes, that sexual crimes of violence were less frequent and venereal disease and bastardy were somehow less common.

Much of his eighteenth-century evidence is consistent with this scenario: members of anti-vice societies of the 1720 s certainly looked back to a time when their reformist activities would not have been needed (though one wonders what they would have made of the sodomy that Trumbach postulates was so common in Puritan Britain). Male libertines such as the Earl of Rochester and other Restoration rakes of the 1670 s were far more likely to practise sodomy than were the eighteenth-century libertines who followed them. At the same time, one wants more from Trumbach about sexual mores in the earlier century, as well as trends in his period.

The full evaluation of Trumbach's stunning thesis must await his second volume, on the 'new' male homosexuality. Whatever one thinks of his explanatory framework, however, there can be nothing but appreciation for the achievement of this fine monograph. Trumbach has given voice to hundreds of ordinary men and women of eighteenthcentury London, whose passions, lusts and tragedies have been reconstructed here with sensitivity and humanity.

W. F. Bynum is at the Wellcome Institute for the

History of Medicine, 183 Euston Road,

London NW1 2BE, UK. 